\title{
Family Values, Competition And The Environment: An International Study Of Business Ethics
}

\author{
Richard A. Bernardi (E-mail: rbernardi@ @wu.edu), Roger Williams University, USA
}

Shelby P. Long, Roger Williams University, USA

\begin{abstract}
This study compares the attitudes of international college students concerning personal versus business ethics, the environment, and competition. The sample consists of 999 business students from Canada, Colombia, Ecuador, Hong Kong, Ireland, Japan, South Africa, Spain, and the United States. While Hofstede's cultural constructs were significant for two of our five research questions (one dealing with family values and the other with ethical practices), Paulus' (1986) Image Management Subscale was significant for three of the research questions. Our data do not support gender differences in ethical sensitivity after controlling for social desirability response bias on an international sample.
\end{abstract}

\section{Introduction}

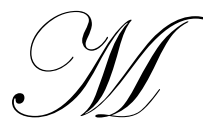

any believe that the lack of a moral compass has led us to today's world of unethical business practices. The cause of the dilemma may be a difference in whether one views ethics as absolute values or whether they are perceived as situation dependent (Sherman, 2002). Business students and business executives indicated that family training was the most influential aspect of their ethical conduct (Arlow and Ulrich, 1988). For instance, Sherman reports that 1,000 (500) adolescents begin drinking alcohol (using illicit drugs) every day in the United States; however, drug use by teenagers whose parents set clear rules is 59 percent lower than for teenagers in general. While this may be the case, Arruda (1997) and Taka (1997) note that family values do not carry forward to the work environment in Latin America and Japan.

This paper discusses cultural differences in the context of business versus personal values, conserving natural resources, and competitive advantage and competition. We propose six hypotheses using Hofstede's (1980) Uncertainty Avoidance and Individualism constructs. Our study builds on Prasad et al.'s (1998) study by comparing the attitudes of business students from five geographic areas and nine countries including two from North America (Canada and the United States), two from South America (Colombia and Ecuador), two from Europe (Ireland and Spain), two from Asia (Hong Kong and Japan) and one from Africa (South Africa).

\section{Theory Development}

\subsection{Overview}

Ethics can vary greatly between different cultures (Ferrel et al., 2002). Some of the variation in ethical perceptions can be explained by cultural relativism, which refers to the degree of similarity of ethics across cultures (Ferrell et al.). One feature of cultural relativism is that, while cultural affects what is considered moral, value judgments are not made about which standard is better (Robertson et al., 2000). Cultural relativism does not neglect the notion that there are certain issues that all cultures view as immoral. While cultural relativism has been debated 
due to the difficulty in measuring cultural differences, it has been proven that ethical perceptions vary among cultures, which is why to understand how "the different cultural dimensions [of Hofstede] impact on the ethical decision-making process across different societies" (Vitell et al., 1993, p. 759).

Hofstede (1980) identifies four cultural dimensions to interpret cross-cultural differences: Individualism, Uncertainty Avoidance, Masculinity, and Power Distance. These dimensions have been well established and are reliable (Robertson et al., 2000). Hofstede dimensions have been used by governments, businesses, health care, the press, and the general public (Fletcher, 2001: Ketchum, 1993). From a cross-cultural perspective, there is evidence of differences between managers from different cultures (Ronen, 1986; Trompenaars and Hampden-Turner, 1998; Yaconi, 2001).

\subsection{Uncertainty Avoidance}

According to Hofstede (1980), uncertainty about the future is a feature of all humans. Emotional resistance to change is one characteristic of a country with high Uncertainty Avoidance; people from these cultures deal with uncertainty by adhering to traditional ideas and standards. Likewise, Hofstede believes that people in low Uncertainty Avoidance cultures are more flexible in their decision-making processes and live day by day. Hofstede maintains that Uncertainty Avoidance is a function of rule orientation, employment stability and stress. However, when Hofstede finished computing his constructs, he found that Uncertainty Avoidance has much larger values than his other constructs. To remedy this, Hofstede subtracted his raw data from 300; consequently, the highest Uncertainty Avoidance scores are for the countries with the lowest level of Uncertainty Avoidance. In this research we refer to Hofstede's raw scores.

As an example, people use different coping mechanisms to deal with this uncertainty. On an individual level, these mechanisms include technology, law, and religion. Another coping mechanism widely used is corruption (Husted, 1999, p. 186). In uncertain situations, corruption may be a way of securing procedures that otherwise may be impossible to carry out. Hofstede suggests that "strong uncertainty avoidance people are also more tolerant of unfairness" (p. 153).

There is evidence that links cross-cultural ethical sensitivity to Uncertainty Avoidance (Husted, 1999). Research in this area asserts that people in low Uncertainty Avoidance cultures are generally relativistic in their ways of thinking (Hoffman et al, 1998). More individualistic societies are more self-interested and act less ethically when the situation dictates (Hoffman). Consequently, people in a low Uncertainty Avoidance culture, who are relativistic by nature, would be more prone to act in a situational manner. Husted also found that as Uncertainty Avoidance increases, corruption also increases.

Wingate (1997) found that, as Uncertainty Avoidance increased, disclosures of suggested financial data in annual reports increased (Jeurissen and van Luijk, 1991). As Uncertainty Avoidance increased, perceived ethical behavior in European countries decreased. Arnold et al. (2001) found that, as Uncertainty avoidance increased, European auditors estimated higher values for materiality. Consequently, auditors from countries with higher Uncertainty Avoidance would be less likely to report an error of fixed size when compared to countries with lower Uncertainty Avoidance. On the basis of these thoughts, we suggest the following:

H1A: As Uncertainty Avoidance increases, participants will report that they are more likely to use the same ethical standards for both business and personal practices.

Corporations use their codes of ethics to transmit their values to the broader community (Stohs and Brannick, 1999). However, it is not uncommon for employees face situations requiring them to choose between their beliefs and what their company wants (Dunfee and Werhane, 1997). One of the potential areas conflict for corporate values and individual values is the environment. Asgary and Mitschow $(2002,240)$ provide three reasons why there is a heightened concern for the environment. 
First, more attention is given to environmental issues by national and international news media. Second is the externality issue, which recognizes that actions taken in one part of the world will also affect others in the other part of the world. Third is the issue of long-term costs to society for cleaning up the resulting waste.

However, people in high Uncertainty Avoidance cultures are not willing to take risks that are not well calculated (Hofstede, 1980). Consequently, changing the proven profit-making methods to conserve natural resources would cause anxiety in a country with high Uncertainty Avoidance. For these reasons, we propose the following:

H1B: As Uncertainty Avoidance increases, participants will report that they are more emphasis will be placed on conserving natural resources.

Uncertainty avoidance explains 30 percent of the variation of the "summed scores of ethical business conduct" for nine European countries (Jeurissen and van Luijk, 1998, p. 999); these summed scores of ethical business conduct were inversely correlated with Uncertainty Avoidance scores. ${ }^{1}$ In fact, countries with the higher Uncertainty Avoidance scores had the smallest average gap between international perceptions and self-ranked ethical business conduct. The largest average gap was for countries with the lower Uncertainty Avoidance scores; consequently, we believe that:

H1C: As Uncertainty Avoidance increases, individual beliefs about a company looking to other companies to determine its ethical standards will increase.

\subsection{Individualism}

Hofstede defines Individualism as describing "the relationship between the individual and the collectivity which prevails in a given society" (p. 213). Individualists tend to overlook the needs of society to take care of themselves and family members (Hofstede). Collectivists have a stronger group identity and often share common goals; consequently, there is more group accountability (Chen et al., 1998). While people in individualistic cultures are driven by personal values, people in collectivistic cultures are driven by duties, obligations and social norms. Enderle (1997, p. 1476)) maintains that business ethics is:

[A] comprehensive sense that includes issues at the individual, organizational and systemic levels of decision making and acting in business and economic life.

Upchurch believes that an organizations ethical environment "represents the collective moral atmosphere that exerts pressure on an individual's ethical decision making" (1998, p. 1351). Individualism emphasizes individual rights over duties (McCarty and Shrum, 2001). In a business setting, one can expect people from Individualistic cultures to apply their personal standards to assist in ethical decision-making. Conversely, one can expect people in a collectivistic culture to look to others to define what is ethically acceptable. In a Collectivistic society, there is the need to conform to group norms, whereas in an individualistic society, individual decisions are encouraged and praised. Wiley (2000) reports that 68.0 (only 11.0) percent of business professionals reported that the ethical principals they learned in their family (professional organizations) were the most influential.

Individualism reflects the spectrum of beliefs between focusing on the individual's interests to a concern for the entire society in more collectivist societies (Triandis et al., 1988; Triandis, 1984). For example, Hofstede maintains that in more individualistic cultures "everyone is supposed to take care of him or herself and his or her immediate family; "I" consciousness; and self-orientation" (Triandis, 1984, p. 235). Thorne and Saunders (2002, p. 235) suggest that Individualists see "ethical obligations as a constraint while collectivists are more concerned with maintaining their moral ideals of maintaining ... social justice."

One can relate this spectrum of beliefs between Individualistic and Collectivist societies to Kohlberg's (1969) model of moral development. The lower stages of Kohlberg's model are similar to Hofstede's individualistic society where personal interests dictate behavior. The higher stages of Kohlberg's model are equivalent to 
Hofstede's highly collectivist society where societal norms include protecting and maximizing the rights and welfare of all individuals. McDevitt and Van Hise (2002) support this notion and suggest that individuals will rely on their society for guidance in making decisions involving ethical conflicts as their level of moral development increases.

H2A: As individualism increases, people will be more likely to use the same ethical standards for both business and personal practices.

Many societies believe that "consumption has a central status" (Uusitalo, 1991, p. 1); social responsibilities are thought to be less important than the expansion of wealth growing opportunities (Cohen et al., 1995). There are other societies that do not use wealth as a yardstick for measuring achievement; these societies support values such as family and quality of life. Stohs and Brannick (1999, p. 313) describe the "notion that one should take advantage of every opportunity to profit - regardless of whether it hurts others."

H2B: As individualism increases, less emphasis will be placed on conserving natural resources.

According to (Hofstede, 1980), the degree of individualism in an organization's corporate culture will impact the relationship between the person and the organization to which he or she belongs. Pressure on a subordinate to cover up a supervisor's illegal action would be interpreted by an individualistic culture as coercion, while a collectivist culture may not perceive this to be unethical (Cohen et al., 1995). In addition, society's level of individualism/collectivism will have an impact on "members' reasons for complying with organizational requirements" (Hofstede, 1980). In a collectivistic culture, decisions are determined by the group rather than by the individual (Husted, 1999). Hence, organizations in collectivistic cultures do not look within the structure to set ethical standards, but look to others to determine what is ethical.

H2C: As individualism increases, individual beliefs about a company looking to other companies to determine its ethical standards will increase.

\section{Subjects And Measures}

\subsection{Sample}

Our initial sample included the responses of 1,048 business majors from ten countries. We did not use the sample from Nepal and the male students from Ecuador and female students from Japan in our analysis because their sizes were less than 30. Our final sample of 999 students (Table 1) represents five of Wingate's $(1997,143)$ nine cultural areas: More Developed Latin (Spain), Less Developed Latin (Colombia and Ecuador), More Developed Asian (Japan), Asian Colonial (Hong Kong), and Anglo (Canada, Ireland, United States, and South Africa). ${ }^{2}$

Table 1

Sample Sizes By Country And Sex

\begin{tabular}{lccc}
\hline Country & Males & Females & Total \\
\hline Canada & 30 & 44 & 74 \\
Colombia & 51 & 126 & 177 \\
Ecuador & 19 & 51 & 70 \\
Hong Kong & 35 & 55 & 90 \\
Ireland & 69 & 42 & 111 \\
Japan & 44 & 7 & 51 \\
Nepal & 4 & 19 & 23 \\
South Africa & 76 & 55 & 131 \\
Spain & 45 & 36 & 81 \\
United States & 134 & 106 & 240 \\
Total & 507 & 541 & 1,048 \\
\hline Shaded Areas & Samples not used in the analysis. \\
\hline
\end{tabular}




\subsection{Research Instrument}

The research instrument consisted of five questions (Appendix A), Paulus' (1988) impression management questionnaire (Appendix B), and a short background data questionnaire. The instrument was purposely kept short so that the probability of students randomly responding to the questionnaire was minimized. Hofstede cultural constructs are a "set of likely reactions of citizens with a common mental programming" (1991, p. 112). ${ }^{2}$ Hofstede's cultural constructs are the average reaction of individuals from each country; consequently, the responses from each country were averaged to produce a most likely estimate by country and gender. This procedure produced 16 unique estimates for each question (i.e., one male and one female sample for each country in the sample), which we used as the dependent variable (Table 2).

Table 2

Mean Responses By Country And Sex

\begin{tabular}{|c|c|c|c|c|c|c|c|c|c|c|c|c|}
\hline \multirow{2}{*}{$\begin{array}{l}\text { Question } \\
\text { Country/Sex }\end{array}$} & \multicolumn{2}{|c|}{ One } & \multicolumn{2}{|c|}{$\underline{\text { Two }}$} & \multicolumn{2}{|c|}{ Three } & \multicolumn{2}{|c|}{ Four } & \multicolumn{2}{|c|}{$\underline{\text { Five }}$} & \multicolumn{2}{|c|}{$\underline{\text { IMS }}$} \\
\hline & M & $\mathbf{F}$ & M & $\mathbf{F}$ & M & $\mathbf{F}$ & $\mathbf{M}$ & $\mathbf{F}$ & $\mathbf{M}$ & $\mathbf{F}$ & $\mathbf{M}$ & $\mathbf{F}$ \\
\hline Canada & 4.5 & 4.9 & 4.5 & 5.3 & 3.8 & 3.8 & 4.7 & 4.9 & 3.8 & 3.2 & 5.1 & 6.3 \\
\hline Colombia & 3.8 & 3.6 & 5.6 & 5.9 & 3.1 & 3.6 & 5.2 & 5.4 & 2.9 & 2.5 & 7.1 & 7.6 \\
\hline Ecuador & na & 5.0 & na & 5.8 & na & 2.9 & na & 5.3 & na & 2.5 & na & 7.8 \\
\hline Hong Kong & 4.3 & 4.4 & 4.5 & 4.6 & 4.1 & 3.9 & 4.3 & 4.2 & 3.2 & 3.5 & 5.3 & 6.2 \\
\hline Ireland & 4.6 & 4.7 & 4.7 & 5.1 & 4.1 & 4.1 & 4.8 & 5.1 & 3.8 & 4.1 & 5.0 & 5.8 \\
\hline Japan & 3.5 & na & 4.2 & na & 4.8 & na & 4.6 & na & 2.1 & na & 6.1 & na \\
\hline South Africa & 4.6 & 4.9 & 4.8 & 5.5 & 3.9 & 3.7 & 4.4 & 4.9 & 3.5 & 3.5 & 5.2 & 7.3 \\
\hline Spain & 4.5 & 4.3 & 4.6 & 4.9 & 3.6 & 3.0 & 5.4 & 5.1 & 3.7 & 3.4 & 5.4 & 7.3 \\
\hline United States & 4.3 & 4.2 & 4.3 & 4.9 & 4.0 & 3.9 & 4.0 & 4.4 & 4.2 & 3.8 & 4.3 & 4.9 \\
\hline
\end{tabular}

IMS The Impression Management Subscale score (Paulhus, 1986).

Shaded Areas These parts of the sample were not used in the analysis.

The five questions used in our study were taken from Prasad et al.'s (1998) study of gender-based differences in ethical perceptions (Appendix A). The first three questions are very similar in that they address the differences (or lack there of) between the respondent's business and personal ethics. The fourth question addresses the issues of conserving natural resources while risking reduction of corporate profit. The last question involves ethical standards between competitive organizations. For five of the ten countries (Colombia, Ecuador, Japan, Nepal, and Spain), a person translated the survey into a country's language; then, the survey was back-translated by a second person. The surveys were given to the contact person who was usually a professor teaching at a university in the country. The contact person distributed the surveys to business students and returned the completed surveys.

Figure 1

Hofstede's Cultural Constructs

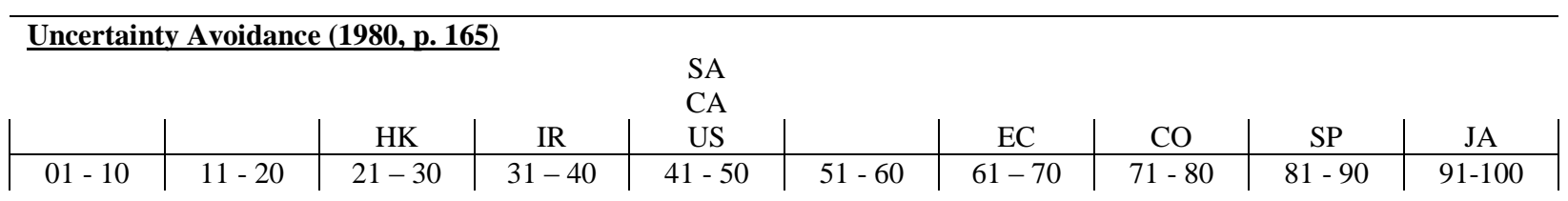

$\underline{\text { Individualism (1980, p. 222) }}$

\begin{tabular}{|c|c|c|c|c|c|c|c|c|c|}
\hline EC & $\mathrm{CO}$ & HK & & JA & SP & $\begin{array}{l}\text { IR } \\
\text { SA } \\
\end{array}$ & CA & & US \\
\hline $01-10$ & $11-20$ & $21-30$ & $31-40$ & $41-50$ & $51-60$ & $61-70$ & $71-80$ & $81-90$ & $91-100$ \\
\hline CA & Canada & & Hong & ong & SA & South Afr & & & \\
\hline $\mathrm{CO}$ & Colombia & & Irelar & & SP & Spain & & & \\
\hline EC & Ecuador & & Japan & & US & United $\mathrm{St}$ & & & \\
\hline
\end{tabular}




\subsection{Hofstede's Cultural Dimensions}

Hofstede's constructs adopted for this survey are Individualism and Uncertainty Avoidance. The first construct used, Individualism, addresses the "relationship between the individual and collectivity which prevails in a given society" (Hofstede 1980, p. 23). This concept implies that those with more individualistic ideals/traits will be more centrally focused on 'self' as opposed to those with more collectivist ideals/traits who will be more concerned with taking principles from a given society. The second construct, Uncertainty Avoidance, involves the fears that a society harbors for uncertain situations (Hofstede, 1980).

The Individualism and Uncertainty Avoidance scores shown in Figure 1 were the result of sampling over 100,000 employees of a multi-national corporation located in 53 countries (Hofstede, 1980). ${ }^{3}$ While Hofstede's initial research is over 20 years old, others been successfully replicated have his data. Smith (2002) (Merritt, 2000) found that the Individualism construct based on the responses of 1,000 accountants from international firms $(9,000$ commercial airline pilots) had a .75 (.67) correlation with Hofstede's (1980) Individualism construct. Smith's data also notes a .69 correlation with Hofstede's Uncertainty Avoidance construct.

\subsection{Control Variables}

In our analysis, we controlled for gender because our questions were selected because Prasad et al. (1998) found significant gender differences. Randall and Gibson (1990) note that only one out of 96 business ethics articles considered social desirability response bias as part of their research design. Consequently, we used the impression management subscale (IMS) of Paulhus' Balanced Inventory of Desirable Responding (1986).

\section{Data Analysis}

\subsection{Personal Versus Business Ethics}

Our hypothesis for the first three questions related to family values and business ethics. Our hypotheses were only partially supported by the data as Table Panels A through C show. Question one (Table 1 Panel A) asked if ethical standards are lower in business than in the typical (country name) family. Our data indicate that as Uncertainty Avoidance scores went up, participants' average responses were lower - remember that the Uncertainty Avoidance scores have been reversed by Hofstede. Consequently, as the Uncertainty Avoidance raw scores increased participants from that country were more likely to agree with the statement.

Question two (Panel B) asked whether the ethical standards participants used in business are as high as those I practice with my family and friends. For this question only Paulhus' Image Management Subscale was significant. In question two, as social desirability response bias increased, participants were more likely to agree with the statement that the ethical standards participants used in business are as high as those I practice with my family and friends - a socially desirable response.

In the third question (Panel C), we asked if participants believed that individuals occasionally make decisions that are right for my business but which are inconsistent with my personal ethical principles. Consequently, questions two and three are stating opposite behavior patterns and one would anticipate that the independent variables would have opposite signs for these questions. Again, Paulhus' Image Management Subscale was the only significant variable. The sign on the IMS variable was negative; consequently, as IMS scores increased, participants were less likely to agree with the statement that individuals occasionally make decisions that are right for my business but which are inconsistent with my personal ethical principles. 
Table 3

Models Relating To Family Values And Business Ethics

\begin{tabular}{|c|c|c|c|c|}
\hline \multicolumn{5}{|c|}{ PANEL A: Business Ethics versus Family Ethics } \\
\hline Model & Rsquare & Adj Rsquare & F Factor & Significance \\
\hline$\overline{\text { Regression }}$ & 0.266 & 0.213 & 5.07 & 0.0409 \\
\hline$\underline{\text { Term }}$ & $\underline{\text { Coefficient }}$ & $\underline{\text { Std Error }}$ & $\underline{\text { T Stat }}$ & $\underline{\mathrm{P} \text {-value }}$ \\
\hline$\overline{\text { Intercept }}$ & 4.98 & 0.28 & $\overline{17.54}$ & $\overline{0.0001}$ \\
\hline Uncertainty Avoidance & -0.01 & 0.00 & -2.25 & 0.0409 \\
\hline \multicolumn{5}{|c|}{ PANEL B: My business ethics are as high as my family ethics } \\
\hline Model & Rsquare & Adj Rsquare & F Factor & $\underline{\text { Significance }}$ \\
\hline$\overline{\text { Regression }}$ & 0.604 & 0.576 & 21.36 & 0.0004 \\
\hline$\underline{\text { Term }}$ & $\underline{\text { Coefficient }}$ & $\underline{\text { Std Error }}$ & T Stat & $\underline{\mathrm{P} \text {-value }}$ \\
\hline Intercept & 2.64 & 0.50 & 5.24 & 0.0001 \\
\hline IMS & 0.38 & 0.08 & 4.62 & 0.0004 \\
\hline \multicolumn{5}{|c|}{ PANEL C: My business ethics are sometimes inconsistent with my family ethics } \\
\hline Model & Rsquare & Adj Rsquare & F Factor & Significance \\
\hline$\overline{\text { Regression }}$ & 0.491 & 0.455 & 13.52 & 0.0025 \\
\hline Term & Coefficient & $\underline{\text { Std Error }}$ & T Stat & P-value \\
\hline$\overline{\text { Intercept }}$ & 5.88 & 0.60 & 9.79 & $\overline{0.0001}$ \\
\hline IMS & -0.36 & 0.10 & -3.68 & 0.0025 \\
\hline
\end{tabular}

\subsection{Environment And Competition}

In the fourth question, we asked if participants believed that one should conserve natural resources even if doing so means reducing corporate profits (Table 4 Panel A). Paulus' IMS variable was again the only significant variable. As socially desirable responsing increased, participants believed that resources should be conserved even at the expense of corporate profits - again a socially desirable response.

Table 4

Models Relating To Family Values And Business Ethics

\begin{tabular}{|c|c|c|c|c|}
\hline Model & Rsquare & Adj Rsquare & F Factor & Significance \\
\hline$\overline{\text { Regression }}$ & $\overline{0.443}$ & 0.403 & $\overline{11.13}$ & 0.0049 \\
\hline Term & Coefficient & $\underline{\text { Std Error }}$ & T Stat & P-value \\
\hline Intercept & 3.17 & 0.49 & 6.41 & 0.0001 \\
\hline IMS & 0.27 & 0.08 & 3.34 & 0.0049 \\
\hline \multicolumn{5}{|c|}{ PANEL B: Ethical Standards Are Determined by Least Ethical Competitor } \\
\hline Model & Rsquare & Adj Rsquare & F Factor & $\underline{\text { Significance }}$ \\
\hline Regression & 0.632 & 0.575 & 11.14 & 0.0015 \\
\hline$\underline{\text { Term }}$ & $\underline{\text { Coefficient }}$ & $\underline{\text { Std Error }}$ & $\underline{\text { T Stat }}$ & $\underline{\text { P-value }}$ \\
\hline Intercept & 3.35 & 0.41 & 8.24 & $\overline{0.0001}$ \\
\hline Individualism & 0.01 & 0.00 & 3.09 & 0.0086 \\
\hline Uncertainty Avoidance & -0.01 & 0.00 & -2.21 & 0.0455 \\
\hline
\end{tabular}


Our last question examined whether participants believed that the ethical standards in a competition are determined by the least ethical competitor; consequently, if one firm engages in unethical conduct, the others will have to follow in order to survive (Table 4 Panel B). Our data indicate that, as Individualism increased, individuals were more likely to agree with the statement. Conversely, as Uncertainty Avoidance increased, individuals were less likely to agree with the statement about competition being driven by the least ethical competitor.

\section{Conclusions}

The data from our large international sample do not support Prasad et al. (1998) who found significant gender differences for the questions we examined. After controlling for social desirability response, our data only partially support our hypotheses dealing with Uncertainty Avoidance and Individuality. In fact, social desirability response bias was the only significant variable in three of our five models. The data in Table 2 indicate that female students tended to have higher scores on Paulus' Image Management Subscale that measures social desirable responding, which suggests the reason for our finding on gender differing from those of Prasad et al. Our findings indicate that researchers should include a control for social desirability response bias in surveys examining ethical questions.

Our data support the point about Hofstede's reversing the sign on his Uncertainty Avoidance construct. While Uncertainty Avoidance was significant for questions one and five, Individualism was only significant for question five. Question one had the strongest association to family in its wording, which could explain its significance for question one. Interestingly, as Individualism increased, participants believed that ethical standards in a competition are determined by the least ethical competitor. This supports our hypothesized association between Hofstede's Individualism/Collectivism construct and Kohlberg's (1969) stages of moral development.

One limitation of this study is that only two of Hofstede's cultural dimensions were used (Uncertainty Avoidance and Individualism). In addition, the surveys were not randomly delivered to college students. Due to the nature of the participants, and the fact that they were selected for their accessibility, we do not claim that they are representative of their respective countries. However, the samples were similar in socioeconomic status and educational level (college students), and therefore were comparable at least among themselves. Our study opens up opportunities for future research using not only Hofstede's values but also other cultural values. Additionally, this study could be extended to other countries and intensified in the countries presented in this paper.

\section{Appendix A: Survey Questions}

Using the scale below as a guide, write a number beside each statement to indicate how much you disagree or agree with it.

\begin{tabular}{c|c|c|c|c|c|c}
1 & 2 & 3 & $\mathbf{4}$ & $\mathbf{5}$ & $\mathbf{6}$ & $\mathbf{7}$ \\
\hline $\begin{array}{c}\text { Strongly } \\
\text { Disagree }\end{array}$ & & & No & & & $\begin{array}{c}\text { Strongly } \\
\text { Agree }\end{array}$
\end{tabular}

1. Ethical standards are lower in business than in the typical (country name) family.

2. The ethical standards I use in business are as high as those I practice with my family and friends.

3. I occasionally make decisions that are right for my business but which are inconsistent with my personal ethical principles.

4. Conserve natural resources even if doing so means a reduction in corporate profits.

5. The ethical standards in a competition are determined by the least ethical competitor. If one firm engages in unethical conduct, the others will have to follow in order to survive. 


\section{Appendix B: Image Management Subscale}

Using the scale below as a guide, write a number beside each statement to indicate how much you agree with it.

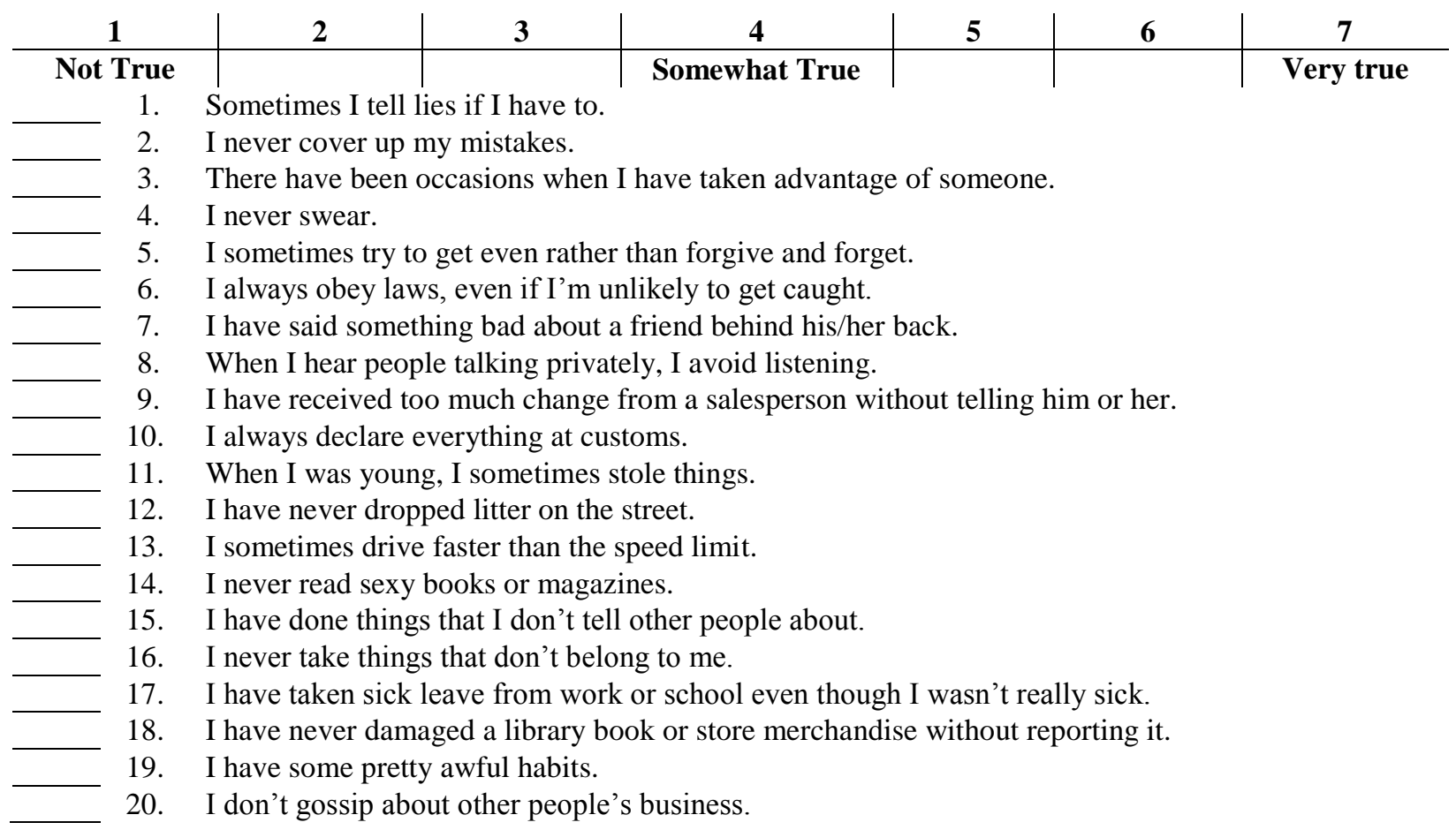

\section{Endnotes}

1. This finding is not part of Jeurissen and van Link's original research; rather, the association was discovered in a secondary analysis the lead author.

2. In each country, there were international students who responded to the survey; these students were eliminated from our sample.

3. While the ranges of 52 (i.e., 92 minus 40) for Uncertainty Avoidance and 83 for Individualism are appropriate for the analysis, the range of 53 for Masculinity is much narrower. If one does not include Japan the range is only 26 . With a Masculinity construct of 95 , Japan is 27 points higher than the next highest country Ireland at 68; consequently, we did not consider Masculinity in the analysis, because the data point from Japan has the potential to dominate the modeling process.

\section{References}

1. Arnold, Donald F., Sr., Richard A. Bernardi, and Presha E. Neidermeyer, 2001. "The Effect of Client Integrity, Litigation, and Culture on European Materiality Estimates", The International Journal of Accounting, Vol. 36 (4), pp. 459-483.

2. Arruda, M. Cecilia, "Business Ethics in Latin America", Journal of Business Ethics, Vol. 16 (14), pp. 1597-1603, 1997.

3. Asgary, Nadar, and Mark C. Mitschow, "Toward a model for international business ethics", Journal of Business Ethics, Vol. 36 (3), pp. 239-246, 2002.

4. Arlow, Peter, and Thomas A. Ulrich, “A Longitudinal Survey of Business School Graduates' Assessments of Business Ethics", Journal of Business Ethics, Vol. 7 (4), pp. 295-302, 1988. 
5. Chen, Chao C., Xia-Ping Chen, James R. Meidl, "How Can Corporation Be Fostered? The Cultural Effects of Individualism- Collectivism”, Academy of Management Review, Vol. 23 (2), pp. 285-305, 1998.

6. Cohen, Jeffrey R; Laurie W. Pant, David J. Sharp, “An Exploratory Examination of International Differences in Auditors' Ethical Perceptions”, Behavioral Research in Accounting, Vol. 7, pp. 37-64, 1995.

7. Dunfee, Thomas W., and Patricia Werhane, "Report on Business Ethics in North America", Journal of Business Ethics, Vol. 16 (14), pp. 1589-1595, 1997.

8. Enderle, Georges, "A Worldwide Survey of Business Ethics in the 1990s", Journal of Business Ethics, Vol. 16 (14), pp. 1475-1483, 1997.

9. Ferrell, O. C., John Fraedrich, and Linda Ferrell, Business Ethics: Ethical Decision Making and Cases, Houghton Mifflin Company, New York, 2002.

10. Fletcher, Richard, "The Complexities of Communicating to Customers in Emerging Markets", Journal of Communication Management, Vol. 6, (1), pp. 9-24, 2001.

11. Hoffman, James J., Grantham Couch, and Bruce L. Lamont, "The Effect of Firm Profit Versus Personal Economic Well Being on the Level of Ethical Responses Given by Managers", Journal of Business Ethics, 17 (3), pp. 239-244, 1998.

12. Hofstede, Geert, Cultures and Organizations: Software of the Mind, McGraw Hill, New York, 1991.

13. Hofstede, Geert, Culture's Consequences: Comparing Values, Behaviors, Institutions, and Organizations across Nations, Sage Publications, Beverly Hills, California, 1980.

14. Husted, Bryan W., "Wealth, Culture, and Corruption”, Journal of International Business Ethics, 30 (2), pp. 339-360, 1999.

15. Jeurissen, R. J. M., and H. J. L. van Luijk, “The Ethical Reputations of Managers in Nine EU-countries: A Cross-referential Survey”, Journal of Business Ethics, 17 (9/10), pp. 995-1005, 1991.

16. Ketchum, S. M., 'Managing the Multicultural Laboratory, Part III: Putting the Cross-Cultural Tools to Work”, Clinical Lab Management Review, 7 (1), pp. 24-33, 1993.

17. Kohlberg, Lawrence, "Stages and Sequences: the Cognitive Developmental Approach to Socialization", in M. Hoffman (Ed.), Handbook of Socialization Theory and Research, Rand McNally, Chicago, IL, 1969.

18. McCarty, John A., and U. Shrum, "The Influence of Individualism, Collectivism, and Locus of Control on Environmental Beliefs and Behavior”, Journal of Public Policy \& Marketing, 20 (1), pp. 93-104, 2001.

19. McDevitt; Roselie, and Joan Van Hise, "Influences in Ethical Dilemmas of Increasing Intensity", Journal of Business Ethics, Vol. 40 (3), pp. 261-274, 2002.

20. Merritt, Ashleigh, "Culture in the Cockpit: Do Hofstede's Dimensions Replicate?", Journal of CrossCultural Psychology, Vol. 31 (3), pp. 283-301, 2000.

21. Paulhus, Delroy L., "Self-Deception and Impression Management in Test Responses", pp. 17-41, in A. Angleiter and J. S. Wiggins (Eds.), Personality Assessment via Questionnaire: Current Issues in Theory and Measurement, Springer-Verlag, Berlin, Germany, 1986.

22. Prasad, Jyoti N., Nancy Marlow, and Richard E. Hattwick, "Gender-based differences in perception of a just society”, Journal of Business Ethics, Vol. 17 (3); pp. 219-228, 1998.

23. Randall, Donna M., and Annetta M. Gibson, "Methodology in Business Ethics Research: A Review and Critical Assessment”, Journal of Business Ethics, Vol. 9 (6), pp. 457-472, 1990.

24. Robertson, Christopher J., Michael K. Brady, William F. Crittenden, and James J. Hoffman, "A Multicultural Test of Personal Versus Firm Ethics", published in The International Marketing Educators Conference Proceedings, Buenos Aires, Argentina.

25. Ronen, Simcha, Comparative and Multinational Management, New York: John Wiley and Sons, 1986.

26. Sherman, Robert, "All about Ethics and Morals", http://home.flash.net/ bob001/, 2002.

27. Smith, Aileen, "Testing the Stability of the Global Concept of Culture in an Accounting Context", Accounting Enquiries, Vol. 11 (2), pp. 227-248, 2002.

28. Stohs, Joanne Hoven, and Teresa Brannick, “Codes and Conduct: Predictors of Irish Managers' Ethical Reasoning”, Journal of Business Ethics, 22 (4), pp. 311-326, 1999.

29. Taka, Iwao, "Business Ethics in Japan”, Journal of Business Ethics, Vol. 16 (14), pp. 1499-1508, 1997.

30. Thorne, Linda, and Susan Bartholomew Saunders, "The Socio-Cultural Embeddedness of Individuals' Ethical Reasoning in Organizations (Cross-Cultural Ethics)", Journal of Business Ethics, Vol. 35 (1), pp. 1-14, 2002. 
31. Triandis, Harry C., "A Theoretical Framework for the More Efficient Construction of Culture Assimilators", International Journal of Intercultural Relations, Vol. 8 (3), pp. 301-330, 1984.

32. Triandis, Harry C., Richard Brislin, and C. Harry Hui, "Cross-Cultural Training across the IndividualismCollectivism Divide", International Journal of Intercultural Relations, Vol. 12, pp. 269-289, 1988.

33. Trompenaars, Fons and Charles Hampden-Turner, Riding the Waves of Culture: Understanding Cultural Diversity in Global Business, New York, NY, McGraw Hill, 1998.

34. Upchurch, Randall S. "A Conceptual Foundation for Ethical Decision Making: A Stakeholder Perspective in the Lodging Industry (USA)", Journal of Business Ethics, Vol. 17 (12), pp. 1349 -1361, 1998.

35. Uusitalo, Outi, "Consumption and Environment", www.cc.jyu.fi/archieve/uusitalo.html, 1995.

36. Velazuez, Manuel, "Globalization and the Failure of Ethics", Business Ethics Quarterly, 10 (1), pp. 343-352, 2000.

37. Vitell, Scott J., Saviour L. Nwachukwu, and James H. Barnes: "The Effects of Culture on Ethical Decision Making: An Application of Hofstede's Typology”, Journal of Business Ethics, 12 (10), pp. 753-760, 1993.

38. Wiley, Carolyn, "Ethical Standards for Human Resource Management Professionals: A Comparative Analysis of Five Major Codes", Journal of Business Ethics, 25 (2), pp. 93-114, 2000.

39. Wingate, Michelle L., "An Examination of Cultural Influence on Audit Environment", Research in Accounting Regulation, Vol. 11 (Supplement), pp 115-127, 1997.

40. Yaconi, Leonardo L., "Cross-Cultural Role Expectations in Nine European Country-Units of a Multinational Enterprise”, The Journal of Management Studies, Vol. 38 (8), pp. 1187-1216, 2001. 
Notes 